\title{
Mild Steel Deterioration Inhibition in 1.0M and 5.0M Tetraoxosulphate (VI) Acid using Leaf Extract of Pterocarpus santaliniodes
}

\author{
OFOMA, EO; EKEMEZIE, P N; *EMERUWA, C N
}

\author{
Department of Pure and Industrial Chemistry, Nnamdi Azikiwe University, Awka, Nigeria \\ *Corresponding author email: emeruwa_chigbundu@yahoo.com. Phone: +2348063615251
}

\begin{abstract}
The prevention of deterioration of mild steel in $1.0 \mathrm{M}$ and $5.0 \mathrm{M} \mathrm{H}_{2} \mathrm{SO}_{4}$ solution by leaf extracts of Pterocarpus santaliniodes was investigated in this study using gravimetric and gasometric methods. Data obtained from the study revealed that leaf extracts had a maximum inhibition efficiency of $88.70 \%$ and $96 \%$ for weight loss and gasometric analysis, respectively for $1.0 \mathrm{M} \mathrm{H}_{2} \mathrm{SO}_{4}$, and an inhibition efficiency of $71.76 \%$ and $79.66 \%$ for weight loss and gasometric analysis respectively for $5.0 \mathrm{M} \mathrm{H}_{2} \mathrm{SO}_{4}$. It was observed that the gasometric method gave the optimum protection. The average activation energy was $73.71 \mathrm{KJ} / \mathrm{mol}$ in $1.0 \mathrm{M} \mathrm{H}_{2} \mathrm{SO}_{4}$, and $74.41 \mathrm{KJ} / \mathrm{mol}$ in $5.0 \mathrm{M} \mathrm{H}_{2} \mathrm{SO}_{4}$. The adsorption of the phytochemicals on the surface of the mild steel were further assessed by the Langmuir and Freundlich isotherms. The extract was found to be good inhibitor for mild steel corrosion in the $\mathrm{H}_{2} \mathrm{SO}_{4}$ solutions. The amount of material loss decreased in the in the presence of the extract when compared to the blank acid solution.
\end{abstract}

\section{DOI: https://dx.doi.org/10.4314/jasem.v22i8.32}

Copyright: Copyright $\odot 2018$ Ofoma et al. This is an open access article distributed under the Creative Commons Attribution License (CCL), which permits unrestricted use, distribution, and reproduction in any medium, provided the original work is properly cited.

Dates: Received: 21April 2018; Revised: 12 August: 2018; Accepted: 24August 2018

Keywords: Mild steel, Corrosion inhibition, $\mathrm{H}_{2} \mathrm{SO}_{4}$, Pterocarpus santaliniodes.

Mild steel corrosion is of theoretical and practical importance. Mild steel is used in the industries for the fabrication of engineering materials, reaction tanks, vessels, and pipes etc which get easily corroded in the presence of acids. Inhibitors are usually introduced to deter the correction process. However some inhibitors are synthetic and toxic to the environment. The search for eco-friendly inhibitors is the major pivot for the use of plant extracts as environmentally friendly inhibitors. In recent times the inhibition of mild steel deterioration by plant extracts has been investigated. Plant extracts have been found to generally show good inhibition efficiencies (Kesavan et al., 2012; Abdullah Dar, 2011).

The results of the several studies showed that the extent of inhibition of mild steel deterioration by the plant extracts generally increases with increase in plant extract concentration. As a contribution to the current interest on environmentally friendly, green corrosion inhibitors, the present study investigates the inhibition efficiency of leaf extract of Pterocarpus santaliniodes on mild steel deterioration in acidic medium using the gravimetric and gasometric techniques. The effect of time and temperature on the inhibition efficiency has also been studied. Kinetic and activation parameters that govern metal corrosion have been studied.

\section{MATERIALS AND METHOD}

Material collection and preparation: $0.08 \mathrm{~cm}$ mild steel sheet obtained from Ahia ohuru main market, Aba in Abia State, Nigeria were mechanically cut into sizes of $5.00 \mathrm{~cm}$ by $2.50 \mathrm{~cm}$. The surfaces of the mild steel coupons were polished with fine grade of sand paper (400 grit size). These polished coupons were then washed thoroughly with distilled water, degreased with methanol, dried with acetone and weighed. The weighed coupons were used for analysis.

Preparation of plant extract: The leaf of Pterocarpus santalinoides was collected from Achina, in Aguata L.G.A of Anambra State, Nigeria. They were pulverized to powder after drying under room temperature. $100 \mathrm{~g}$ of the plant powders were extracted with 4:1 methanol:water (80\% methanol) using a soxhlet extractor for 24 hours. The extract was distilled at $60{ }^{\circ} \mathrm{C}$ in a water bath until almost the entire methanol evaporated.The leaf extract test solutions of concentration 1.0, 2.0, 3.0, 4.0 and $5.0 \mathrm{~g} / \mathrm{L}$ were prepared from the stock solution by dissolving $1 \mathrm{~g}, 2 \mathrm{~g}$, $3 \mathrm{~g}, 4 \mathrm{~g}$ and $5 \mathrm{~g}$ of the methanol extract in $1 \mathrm{M} \mathrm{H}_{2} \mathrm{SO}_{4}$. These solutions were then used for the corrosion inhibition test in the acidic medium. This same process was repeated with $5 \mathrm{M} \mathrm{H}_{2} \mathrm{SO}_{4}$. 
Weight loss technique: The weighed mild steel coupons were completely suspended in a beaker containing $100 \mathrm{~mL}$ each of the test solution at room temperature. The mild steel coupons were retrieved after 6 hours, washed in plenty of water, rinsed in methanol, dried using acetone and re-weighed. This procedure was repeated for 12, 18 and 24 hours using the $1.0 \mathrm{M}$ and $5.0 \mathrm{M}$ test solutions. The weight loss of the mild steel was evaluated in grams as the difference in the initial and final weight of the coupon. From the weight loss data, the corrosion rates (CR) were calculated from the equation 1 below:

$$
\mathrm{CR}=\frac{\mathrm{WL}}{\mathrm{A} \cdot \mathrm{t}}
$$

Where WL is weight loss in $\mathrm{g}$, $\mathrm{A}$ is the specimen surface area and $t$, the period of immersion in hours. From corrosion rate, the inhibition efficiencies of the molecules (I\%) were determined using equation 2.

$$
\mathrm{I} \%=\left[\frac{\mathrm{CR}_{\text {blank }}-\mathrm{CR}_{\text {inh }}}{\mathrm{CR}_{\text {blank }}}\right] \times 100
$$

Where $\mathrm{CR}_{\text {blank }}$ and $\mathrm{CR}_{\text {inh }}$ are the corrosion rates in the absence and presence of the plant extracts respectively.

Gasometric technique:The gasometric technique was conducted using a gasometric assembly which consists of a reaction vessel connected to a burette containing paraffin oil. The burette was also connected to a paraffin oil reservoir. In the gasometric technique, the volume of hydrogen evolved was determined following procedures previously described (Obike et al., 2016). $100 \mathrm{~mL}$ of a test solution was introduced into the reaction vessel. A mild steel coupon was dropped into the solution in the chamber and the reaction vessel was quickly closed to avoid any escape of hydrogen gas. The volume of the hydrogen gas evolved from the reaction was monitored by the depression (in $\mathrm{mL}$ ) in the level of paraffin oil. This depression in the paraffin oil level was recorded every minute for a maximum of 15 minutes at temperatures of 323 and $333 \pm 2 \mathrm{~K}\left(40^{\circ} \mathrm{C}\right.$ and $\left.50^{\circ} \mathrm{C}\right)$. This procedure was repeated for blank and other concentrations of the test solutions for $1.0 \mathrm{M}$ and $5.0 \mathrm{M}$ acids. The rate of evolution of the hydrogen gas (Rh) is determined from the slope of the graph of volume of hydrogen gas evolved $(\mathrm{Vh})$ versus time $(\mathrm{t})$ and the inhibition efficiency (I\%) determined using the equation below.

$$
\mathrm{I} \%=\left[\frac{\mathrm{Rh}_{\text {blank }}-\mathrm{Rh}_{\text {inh }}}{\mathrm{Rh}_{\text {blank }}}\right] \times \frac{100}{1}
$$

Where $R h_{\text {blank }}$ and $R h_{\text {inh }}$ are the corrosion rates in the absence and presence of plant extract respectively.
Activation and adsorption parameters: In examining the effect of temperature on the corrosion process, the activation energy $\left(E_{a}\right)$ was calculated using the condensed Arrhenius equation below

$$
E_{a}=2.303 R\left[\log \left(\frac{R_{2}}{R_{1}}\right) \times \frac{T_{1} T_{2}}{T_{2}-T_{1}}\right]
$$

Where $R_{1}$ and $R_{2}$ are the corrosion rates at temperatures $T_{1}$ and $T_{2}$ respectively, and $\mathrm{R}$ is the molar gas constant. An estimate of the heat of adsorption $\left(Q_{\text {ads }}\right)$ was obtained from the trend of surface coverage $(\theta)$ with temperature (T) as follows;

$$
\mathrm{Q}_{\mathrm{ads}}=2.303 \mathrm{R}\left[\log \left(\frac{\theta_{2}}{1 \times \theta_{2}}\right)-\log \left(\frac{\theta_{1}}{1 \times \theta_{1}}\right) \times \frac{\mathrm{T}_{1} \mathrm{~T}_{2}}{\mathrm{~T}_{2}-\mathrm{T}_{1}}\right]
$$

Where $\theta_{1}$ and $\theta_{2}$ are the degrees of surface coverage at temperature $T_{1}$ and $T_{2}$ respectively.

The data of the study were subjected Langmuir and Freundlich adsorption isotherm according to equations 6 and 7 respectively:

$$
\begin{aligned}
\frac{c}{\theta} & =\frac{1}{K_{a d s}}+c \quad(6) \\
\log \theta & =\log K+n \log C
\end{aligned}
$$

Where $\theta$ is the surface coverage, $\mathrm{C}$ is the concentration, $\mathrm{n}$ is the intensity of the adsorbent and $\mathrm{K}$ and $\mathrm{K}_{\mathrm{ads}}$ are the equilibrium constant of the adsorption for Langmuir and Freundlich respectively.

The standard Gibbs free energy was calculated using equation 8

$$
\Delta \mathrm{G}_{\mathrm{ads}}=-2.303 \mathrm{RTLog}\left(55.5 \mathrm{~K}_{\mathrm{ads}}\right)
$$

As the reactions were carried out at constant pressures, values of $\mathrm{Q}_{\mathrm{ads}}$ should approximate those of the enthalpy of adsorption $\left(\Delta \mathrm{H}_{\mathrm{ads}}\right)$ (Sharma and Sharma, $1999)$. Thus the entropy of adsorption, $\left(\Delta \mathrm{S}_{\mathrm{ads}}\right)$ was calculated using equation 9

$$
\Delta \mathrm{G}_{\mathrm{ads}}=\Delta \mathrm{H}_{\mathrm{ads}}-\mathrm{T} \Delta \mathrm{S}_{\mathrm{ads}}
$$

\section{RESULTS AND DISCUSSION}

Weight loss measurement: The weight loss (g) and percentage inhibition efficiency of mild steel in $1.0 \mathrm{M}$ and $5.0 \mathrm{M} \mathrm{H}_{2} \mathrm{SO}_{4}$ in the absence and presence of different concentrations of leaf extracts of Pterocarpus santalinoides at ambient temperature are shown in Table 1.From the, it could be seen that the inhibition efficiency, in both $1.0 \mathrm{M}$ and $5.0 \mathrm{M}$, increased with increase in the concentrations of the extract. However, the inhibition efficiency apparently decreased over time. These were in line with the 
findings of Udom et al., 2017; Karthiga et al., (2018); Ali and Suleiman (2018). It was observed that $5.0 \mathrm{~g} / \mathrm{L}$ of the extract at 6hours in both $1.0 \mathrm{M}$ and $5.0 \mathrm{M}$ gave the best corrosion inhibition with an inhibition efficiency of $88.7 \%$ and $71.76 \%$ respectively. Comparison of the results showed that the leaf extract acts as a better inhibitor at lower acid concentration. The decrease in the value of percentage inhibition efficiency with immersion time may be ascribed to an increase in desorption of the plant constituents from the metal surface while an increase in inhibition efficiency may refer to a decrease in desorption of the inhibitor molecules from the metal surface (Olusegun et al., 2011).

Gasometric results: The values for the rate of hydrogen evolution and inhibition efficiency for $1.0 \mathrm{M}$ and 5.0M are shown in Tables 2. From Table 2 it was observed that the presence of the leaf extract decreased the volume of hydrogen evolved as evidenced in the decreasing rate of hydrogen evolution, and indicative of decreasing rate of corrosion when compared with the blank. The values in the table also showed that the rate of hydrogen evolution increased with increase in temperature and reduced with increase in the concentration of the plant extract. Reduction in the rate of hydrogen evolution with increase in plant extract was an indication that the plant extracts inhibited the mild steel corrosion. Similar results were obtained by Ikpi et al., (2012) in their study. The reduction in corrosion was as a result of the adsorption of the extracts on the surface of the metal steel separating it from the medium (Chibowski et al., 20005; El-Etre, 2007). From the rate of hydrogen evolution, the inhibition efficiencies were determined. It was observed that the inhibition efficiency increased with increase in the concentration of the plant extract and decreased with increase in temperature. This result also points to the fact that the leaf extract can serve as a corrosion inhibitor.

Table 1: Results of weight loss (g) and percentage inhibition efficiency

\begin{tabular}{llllllllllll}
\hline \multicolumn{1}{c}{ Weight Loss } & \multicolumn{5}{c}{ \% Inhibition efficiency } \\
\hline & Blank & $1.0 \mathrm{~g} / \mathrm{L}$ & $2.0 \mathrm{~g} / \mathrm{L}$ & $3.0 \mathrm{~g} / \mathrm{L}$ & $4.0 \mathrm{~g} / \mathrm{L}$ & $5.0 \mathrm{~g} / \mathrm{L}$ & $1.0 \mathrm{~g} / \mathrm{L}$ & $2.0 \mathrm{~g} / \mathrm{L}$ & $3.0 \mathrm{~g} / \mathrm{L}$ & $4.0 \mathrm{~g} / \mathrm{L}$ & $5.0 \mathrm{~g} / \mathrm{L}$ \\
\hline $\mathbf{1 . 0} \mathbf{M}$ & & & & & & & & & & & \\
$6 \mathrm{hr}$ & 0.62 & 0.26 & 0.24 & 0.15 & 0.11 & 0.07 & 58.05 & 61.28 & 75.80 & 82.25 & 88.71 \\
$12 \mathrm{hr}$ & 1.05 & 0.60 & 0.41 & 0.36 & 0.30 & 0.22 & 42.91 & 60.99 & 65.74 & 71.45 & 79.07 \\
$18 \mathrm{hr}$ & 1.60 & 0.86 & 0.74 & 0.49 & 0.35 & 0.25 & 46.23 & 53.74 & 69.37 & 78.12 & 84.37 \\
$24 \mathrm{hr}$ & 1.71 & 1.03 & 0.85 & 0.67 & 0.50 & 0.46 & 39.74 & 50.27 & 60.81 & 70.75 & 73.09 \\
$\mathbf{5 . 0} \mathbf{M}$ & & & & & & & & & & & \\
$6 \mathrm{hr}$ & 1.37 & 0.67 & 0.61 & 0.60 & 0.50 & 0.39 & 51.11 & 55.49 & 56.36 & 63.88 & 71.76 \\
$12 \mathrm{hr}$ & 2.75 & 1.42 & 1.32 & 1.28 & 1.13 & 1.08 & 48.41 & 52.04 & 53.50 & 58.80 & 60.69 \\
$18 \mathrm{hr}$ & 4.10 & 2.80 & 2.77 & 2.58 & 2.49 & 2.37 & 31.70 & 32.44 & 37.07 & 39.34 & 42.10 \\
$24 \mathrm{hr}$ & 4.51 & 3.78 & 3.77 & 3.54 & 3.48 & 3.30 & 16.15 & 16.44 & 21.54 & 22.94 & 26.90 \\
\hline
\end{tabular}

Table 2: Results of rate of hydrogen evolution ( $\mathrm{mL} / \mathrm{min}$ ) and inhibition efficiency (\%)

\begin{tabular}{|c|c|c|c|c|c|c|c|c|c|c|c|}
\hline & \multicolumn{6}{|c|}{ Rate of hydrogen evolution(mL/min) } & \multicolumn{5}{|c|}{ Inhibition efficiency (\%) } \\
\hline & Blank & $1.0 \mathrm{~g} / \mathrm{L}$ & $2.0 \mathrm{~g} / \mathrm{L}$ & $3.0 \mathrm{~g} / \mathrm{L}$ & $4.0 \mathrm{~g} / \mathrm{L}$ & $5.0 \mathrm{~g} / \mathrm{L}$ & $1.0 \mathrm{~g} / \mathrm{L}$ & $2.0 \mathrm{~g} / \mathrm{L}$ & $3.0 \mathrm{~g} / \mathrm{L}$ & $4.0 \mathrm{~g} / \mathrm{L}$ & $5.0 \mathrm{~g} / \mathrm{L}$ \\
\hline 1.0 M & & & & & & & & & & & \\
\hline $313 \mathrm{~K}$ & 0.85 & 0.47 & 0.33 & 0.22 & 0.17 & 0.16 & 87.96 & 91.64 & 94.36 & 95.64 & 96.00 \\
\hline $323 \mathrm{~K}$ & 1.93 & 0.90 & 0.69 & 0.52 & 0.50 & 0.45 & 84.21 & 87.91 & 90.85 & 91.27 & 92.02 \\
\hline $5.0 \mathrm{M}$ & & & & & & & & & & & \\
\hline $313 \mathrm{~K}$ & 3.98 & 1.56 & 1.29 & 0.90 & 0.68 & 0.32 & 60.73 & 67.48 & 77.41 & 82.99 & 92.05 \\
\hline $323 \mathrm{~K}$ & 6.18 & 3.34 & 2.64 & 1.99 & 1.47 & 1.26 & 45.98 & 57.27 & 67.80 & 76.29 & 79.66 \\
\hline
\end{tabular}

Table 3: Calculated values of $\mathrm{E}_{\mathrm{a}}$ and $\mathrm{Q}_{\text {ads }}$ for leaf extract in 1.0M and 5.0M H $\mathrm{H}_{2} \mathrm{SO}_{4}$

\begin{tabular}{cccccccccccc}
\hline & \multicolumn{9}{c}{$\mathrm{Ea}$} & \multicolumn{4}{c}{$\mathrm{Q}_{\text {ads }}$} \\
\hline & Blank & $\mathbf{1 . 0 g} / \mathbf{L}$ & $\mathbf{2 . 0 g} / \mathbf{L}$ & $\mathbf{3 . 0 g} / \mathbf{L}$ & $\mathbf{4 . 0 g} / \mathbf{L}$ & $\mathbf{5 . 0 g} / \mathbf{L}$ & $\mathbf{1 . 0 g} / \mathbf{L}$ & $\mathbf{2 . 0 g} / \mathbf{L}$ & $\mathbf{3 . 0 g} / \mathbf{L}$ & $\mathbf{4 . 0 g} / \mathbf{L}$ & $\mathbf{5 . 0 g} / \mathbf{L}$ \\
\hline $\mathbf{1 . 0 M}$ & 68.64 & 54.34 & 62.49 & 72.26 & 89.92 & 89.55 & -26.47 & -34.45 & -43.91 & -62.32 & -61.57 \\
$\mathbf{5 . 0 M}$ & 37.12 & 63.93 & 60.09 & 66.92 & 65.04 & 116.09 & -50.19 & -36.76 & -40.95 & -34.99 & -91.12 \\
\hline
\end{tabular}

Table 4: Values of $K_{a d s}, R^{2}, \Delta G_{\text {ads }}$ and $\Delta S_{\text {ads }}$ from Langmuir and Freundlich Isotherm

\begin{tabular}{ccccccccc}
\hline & \multicolumn{3}{c}{ Langmuir Isotherm $\left(1.0 \mathrm{M} \mathrm{H}_{2} \mathrm{SO}_{4}\right)$} & \multicolumn{4}{c}{ Freundlich Isotherm $\left(1.0 \mathrm{M} \mathrm{H}_{2} \mathrm{SO}_{4}\right)$} \\
\hline & $\mathrm{K}_{\text {ads }}$ & \multicolumn{1}{c}{$\mathbf{R}^{2}$} & $\Delta \mathrm{G}_{\text {ads }}$ & $\Delta \mathrm{S}_{\text {ads }}$ & $\mathrm{K}_{\text {ads }}$ & $\mathbf{R}^{2}$ & $\Delta \mathrm{G}_{\text {ads }}$ & $\Delta \mathrm{S}_{\text {ads }}$ \\
\hline $\mathbf{1 . 0} \mathbf{M}$ & & & & & & & & \\
$313 \mathrm{~K}$ & 7.4019 & 0.9894 & -15.6637 & 0.0386 & 0.8813 & 0.9845 & -10.1246 & 0.0210 \\
$323 \mathrm{~K}$ & 7.3314 & 0.9925 & -16.1384 & 0.0402 & 0.8449 & 0.9715 & -10.3349 & 0.0216 \\
$\mathbf{5 . 0} \mathbf{M}$ & & & & & & & & \\
$313 \mathrm{~K}$ & 1.1029 & 0.9808 & -10.7086 & -0.0090 & 0.5970 & 0.9376 & -9.1112 & 0.0177 \\
$323 \mathrm{~K}$ & 0.6133 & 0.9915 & -9.1815 & -0.0138 & 0.4097 & 0.9949 & -8.3911 & 0.0154 \\
\hline
\end{tabular}


Activation parameters and adsorption isotherm:The values of $\mathrm{E}_{\mathrm{a}}$, and $\mathrm{Q}_{\mathrm{ads}}$, for the corrosion of mild steel with the plant extract in $1.0 \mathrm{M}$ and $5.0 \mathrm{M} \mathrm{H}_{2} \mathrm{SO}_{4}$ are given in Table 3.Table 3 showed that $\mathrm{E}_{\mathrm{a}}$ values for $1.0 \mathrm{M} \mathrm{H}_{2} \mathrm{SO}_{4}$ increased in the presence of the leaf extracts. For $5.0 \mathrm{M} \mathrm{H}_{2} \mathrm{SO}_{4}$, these values were higher than the values for blank which is typical of physical adsorption (Martinez and Stern, 2002). Further inspection of the results as given in Table 3 revealed that $E_{a}$ values apparently increased with increase in the concentrations of plant extracts, meaning higher protection efficiency was attained due to increase in the energy barrier for the reaction.

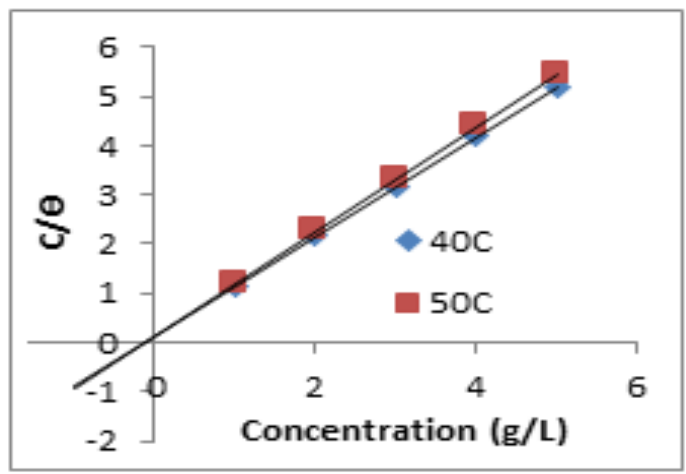

Fig 1: Langmuir plot for leaf in $1.0 \mathrm{M} \mathrm{H}_{2} \mathrm{SO}$

The negative values of $Q_{\text {ads }}$ were an indication that the processes were exothermic. The average activation energy values of the inhibitors reported were calculated to be $73.71 \mathrm{~kJ} / \mathrm{mol}$ for $1.0 \mathrm{M} \mathrm{H}_{2} \mathrm{SO}_{4}$ and $74.41 \mathrm{~kJ} / \mathrm{mol}$ for $5.0 \mathrm{M} \mathrm{H}_{2} \mathrm{SO}_{4}$. These values confirmed the assertion that the process of inhibition is by physical adsorption (Atkin and de Paula, 2006). According to the author, the activation energy for physical adsorption should be small and not be up to $200 \mathrm{~kJ} / \mathrm{mol}$ as at that large value of $E_{a}$ chemical adsorption is experienced.

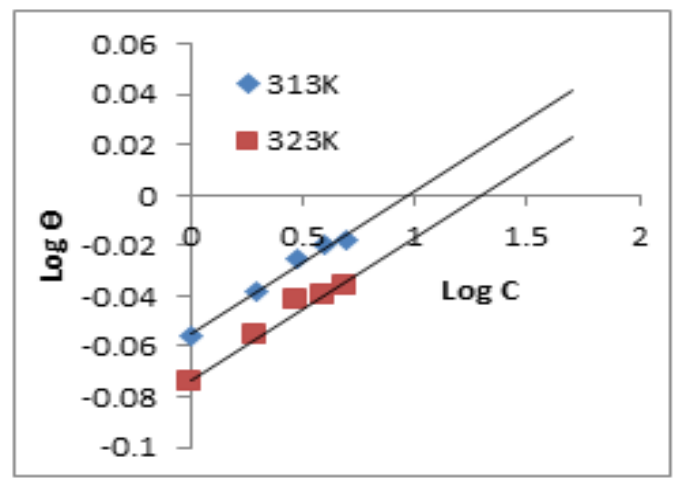

Fig 2: Freundlich plot for leaf extract in $1.0 \mathrm{M} \mathrm{H}_{2} \mathrm{SO}_{4}$

The Langmuir isotherm and Freundlich isotherm were employed to fit the experimental data as shown in Figures 1 to 4 . Table 4 showed the linear correlation coefficient $\mathrm{R}^{2}$, of the fitted data. The $\mathrm{K}_{\mathrm{ads}}$ values were gotten from the reciprocal of the intercept for Langmuir Isotherm and the anti-log of the intercept for Freundlich Isotherm and they were subsequently used to evaluate $\Delta \mathrm{G}_{\mathrm{ads}}$, and $\Delta \mathrm{S}_{\mathrm{ads}}$ using equations 8 and 9 respectively. The values are presented in Table 4 for 1.0M.The values for entropy of adsorption, $\left(\Delta \mathrm{S}_{\text {ads }}\right)$ were calculated by substituting corresponding values of $\Delta \mathrm{G}_{\mathrm{ads}}$ and $\Delta \mathrm{H}_{\mathrm{ads}}$ into equation 9.

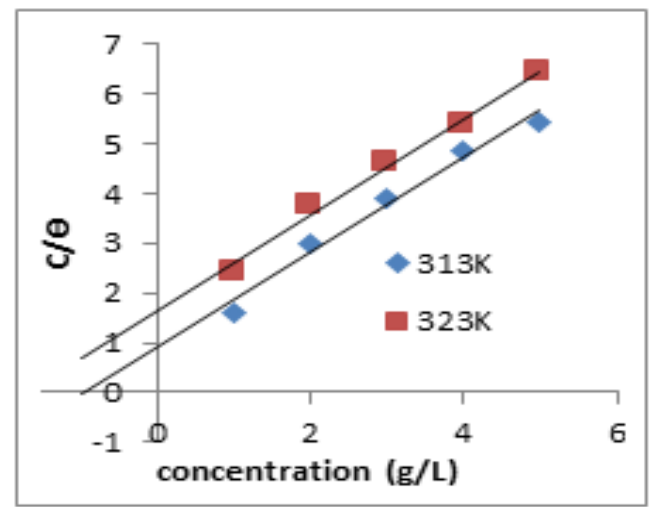

Fig 3: Langmuir plot for leaf extract in $5 \mathrm{M} \mathrm{H}_{2} \mathrm{SO}_{4}$

Taking into account that as the reactions were carried out at constant pressures, values of $Q_{\text {ads }}$ should approximate those of the enthalpy of adsorption $\left(\Delta H_{\text {ads }}\right)$ (Sharma and Sharma, 1999). The negative values for $\Delta \mathrm{G}_{\mathrm{ads}}$ as seen in Tables 4 indicate that the reaction was spontaneous and feasible. From Table 4, the values of $\Delta \mathrm{G}_{\mathrm{ads}}$ are more positive than $-20 \mathrm{kJmol}^{-1}$ signifying physical adsorption.

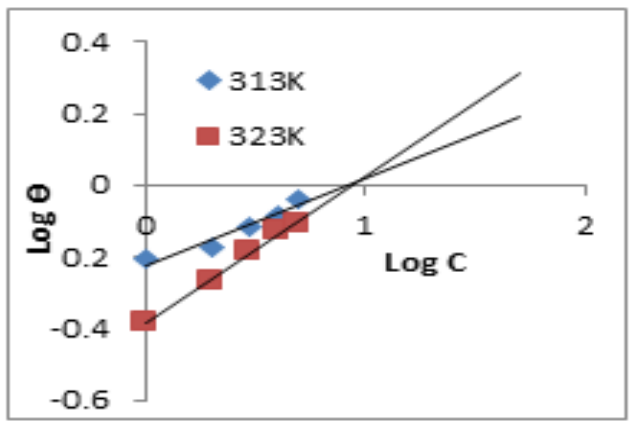

Fig 4: Freundlich plot for leaf extract in $5 \mathrm{M} \mathrm{H}_{2} \mathrm{SO}_{4}$

Generally, values of $\Delta \mathrm{G}_{\text {ads }}$ are more positive than -20 $\mathrm{kJ} \mathrm{mol}^{-1}$ are consistent with electrostatic interactions between the charged metal which signifies physical adsorption while values more negative than $-40 \mathrm{~kJ}$ $\mathrm{mol}^{-1}$ involved charge sharing or transfer from the inhibitor molecules to the metal surface to form coordinate type of bond which signifies chemical adsorption (Umoren et al., 2006). Figures 1 to 4 showed the plot for Langmuir and Freundlich 
isotherm. A comparison of the correlation coefficients of the Langmuir and Freundlich isotherms as presented in Table 4 showed that at $1.0 \mathrm{M} \mathrm{H}_{2} \mathrm{SO}_{4}$ the data fitted more to Langmuir than Freundlich isotherm. But for $5.0 \mathrm{M} \mathrm{H}_{2} \mathrm{SO}_{4}$, the data fitted more to Freundlich isotherm than Langmuir isotherm. Langmuir isotherm postulate monolayer adsorption of the adsorbate onto the adsorbent which was expected to have a correlation coefficient of unity (Ating et al., 2010). The $R^{2}$ value was also an indication that the plant extracts components are approximated by Langmuir adsorption and the monolayer of the extract species must have been attached to mild metal surface without lateral interaction between the adsorbed species. The values of $K_{a d s}$ were seen to decrease as the temperature rises from $313 \mathrm{~K}$ to $323 \mathrm{~K}$ in all the cases. This further confirms that the inhibitors were physically adsorbed on the surface of the mild steel (Ikpi et al., 2012).

Conclusion: Methanol extracts of leaf of Pterocarpus santalinoides were found to be inhibitors for mild steel corrosion in $1.0 \mathrm{M}$ and $5.0 \mathrm{M} \mathrm{H}_{2} \mathrm{SO}_{4}$ solution. It was observed that the corrosion inhibition efficiency was higher in $1 \mathrm{M} \mathrm{H}_{2} \mathrm{SO}_{4}$. The mechanism of adsorption proposed for the extract is physical adsorption. This is evidenced from the calculated average activation energy and the decreasing values of $K_{a d s}$ from the adsorption isotherms. The corrosion inhibition is attributed to physical adsorption of the phytochemical components of the extracts on the surface of the metal.

\section{REFERENCES}

Abdullah Dar, M, (2011). A review: plant extracts and oils as corrosion inhibitors in aggressive media, Ind. Lub. Tri, 63(4): 227-233.

Ali, IH; Suleiman, MHA (2018). Effect of Acid Extract of Leaves of Juniperus procera on Corrosion Inhibition of Carbon Steel in $\mathrm{HCl}$ Solutions. Int. J. Electrochem. Sci., 13: 3910 - 3922.

Ating, EI; Umoren, SA; Udousoro, II; Ebenso, EE; Udoh, AP (2010). Leaves extract of Ananas sativum as green corrosion inhibitor for aluminium in hydrochloric acid solutions. Green Chem. Lett. Rev. 3 (2): 61-68.

Atkin, P; Paula, J (2006). Atkins' Physical Chemistry, 8th Edition. W. H. Freeman and Company, New York. pp 916-917

Chibowski, S; OpalaMuzur, OE; Patkowski, J (2005). Influence of the ionic strength on the adsorption properties of the system dispersed aluminium oxidepolyacrylic acid. Mater. Chem. and Phys. 93: 262271.
El-Etre, AY (2007). Inhibition of acid corrosion of carbon steel using aqueous extract of olive leaves. $J$. Colloid Interface. Sci. 314(2): 578-583.

Ikpi, ME; Udoh, II; Okafor, PC; Ekpe, UJ; Ebenso, EE (2012). Corrosion Inhibition and Adsorption Behaviour of Extracts from Piper guineensison Mild Steel Corrosion in Acid Media. Int. J. Electrochem. Sci. 7: $12193-12206$.

Karthiga, N; Rajendran, S; Prabhakar, P; Al-Hashem, A; Hanmugapriya, S (2018). Corrosion inhibition of mild steel by an aqueous extract of Allium sativum.Euro. J. Biomed. Pharma. Sci. 2(4): 31-49.

Kesavan, D; Gopiraman, M; Sulochana, N (2012). Green Inhibitors for Corrosion of Metals: A Review. Chem. Sci. Rev. Lett. 1(1): 1-8

Martinez, S; Stern, I. (2002), Thermodynamic characterization of metal dissolution and inhibitor adsorption processes in the low carbon steel/mimosa tannin/sulfuric acid system. App. Surf. Sci., 199: 8389.

Obike, AI; Emeruwa, CN; Ajiwe, VIE; Igwe, JC. (2016). Corrosion Inhibition and Adsorption Behaviour of Methanol Extract of Spondias cytherea leaves on Mild Steel Corrosion in 5.0M H $\mathrm{SO}_{4}$, Int. J. of Inno. Res. in Sci. Eng. Tech., 5(6): 9501-9510.

Olusegun, KA; Moriamo, OJ; Patrick, OA; Peter, CO; Oladele, OJ (2011), '3-[(4- amino-2-methyl-5pyrimidinyl) methyl]-5-(2-hydroxyethyl)-4- methyl thiazolium chloride hydrochloride as green corrosion inhibitor of copper in $\mathrm{HNO}_{3}$ solution and its adsorption characteristics. Green Chem. Lett. Rev. 4(3): 273-279.

Sharma, KK; Sharma, LK (1999). A textbook of Physical Chemistry, $9^{\text {th }}$ edition, New Delhi: Viska Publishers. pp 26-49.

Udom, GI; Cookey, GA; Abia, AA (2017). The Effect of Acanthus montanus Leaves Extract on Corrosion of Aluminium in Hydrochloric Acid Medium. Curr. J. of App. Sci. and Tech. 25(2): 1-11

Umoren, SA; Obot, IE; Ebenso, EE; Okafor PC; Ogbobe O; Okezie EE (2006), Gum arabic as a potential corrosion inhibitor for aluminium in alkaline medium and its adsorption characteristics. Anti-Corr Meth and Mat, 53(5), 277-282. 